\title{
A Vision for Hospital Pharmacy in Canada
}

\author{
Neil J MacKinnon
}

Where there is no vision, the people perish. - Proverbs 29:18a (King James version)

A $s$ many of you are aware, each of the 3 presidential officers of CSHP holds a different portfolio (external, internal, or vision) for the duration of his or her 3-year term. As the current Vision Liaison, I am not charged with personally creating a vision for hospital pharmacy in Canada (thank goodness), but many of my duties deal with planning, monitoring, and measuring whether our Society is achieving its objectives.

So what exactly is meant by the word "vision"? As King Solomon observed roughly 3000 years ago in the proverb quoted above, a vision can be highly influential and powerful. The Merriam-Webster's Dictionary contains several definitions of "vision" as a noun, including "a thought, concept, or object formed by the imagination" - not likely the type of vision to which Solomon was referring or to which the CSHP Vision Liaison relates. A more relevant definition would seem to be "an idea or a goal toward which one aspires".

CSHP's Vision 2011, adopted in 2007, is to be a dynamic society, the influential voice for hospital pharmacy, inspiring practice excellence, and fostering leadership and professional growth. CSHP has several performance measures in place, which are monitored regularly to help in the achievement of this vision. In particular, a new strategic business plan, being developed at the time of writing this column, will help to direct CSHP over the next 3 years.

What is CSHP's vision for hospital pharmacy practice in Canada? One of the most tangible ways in which CSHP articulates its vision is via CSHP 2015, a practice excellence initiative for pharmacists in hospitals and related health care settings. The overall aim of this initiative is to enhance the effective, scientific, and safe use of medications and to contribute meaningfully to public health, thereby participating in the health of Canadians. This aim will be accomplished by the achievement of 6 goals and 36 underlying measurable objectives.

CSHP has also endorsed the vision for pharmacy enunciated in the Blueprint for Pharmacy (see www.pharmacists.ca/ content/ about_cpha/whats_happening/cpha_in_action/pdf/ BlueprintVision.pdf): "Optimal drug therapy outcomes for
Canadians through patientcentred care". CSHP continues to work as an active partner with several other pharmacy organizations in implementing this vision for our profession. For example, this fall CSHP will be participating in the Pharmacy Practice Model Initiative of the American Society of Health-System

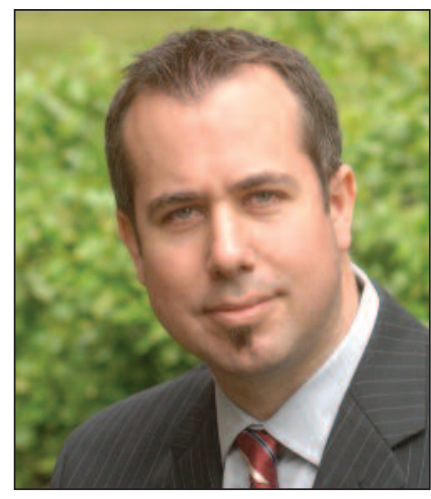

Pharmacists, helping to cast a new vision specifically for hospital pharmacy practice.

It is also worth noting that "vision" can also function as a verb. Some sources define the verb "vision" as "to dream." This relationship between dreaming and visioning was captured by Dr Charles D Hepler in the 2010 H A K Whitney Award address (given during the ASHP Summer Meeting and Exhibition in June 2010; see Am J Health Syst Pharm 2010;67[16]: 1319-1325), in which he stated, "The dream of pharmacy as a clinical profession has been deferred too long" and "There will never be a better time for us to make our dream deferred into a vision achieved."

As a profession, we have made incredible progress over the past few decades, with the rise of clinical pharmacy and pharmaceutical care. Still, admittedly, there is much work to be done. Pharmacists are not providing pharmaceutical care to every patient in our nation's hospitals, and there are patients for whom the medication-use system is neither safe nor effective. My personal challenge to you is to consider "vision" as both a noun and a verb in your own practice area as you dream about new services and strive toward the targets in CSHP 2015.

Neil J MacKinnon, BSc(Pharm), MSc(Pharm), PhD, FCSHP, is President and Vision Liaison of CSHP. 